\title{
Study on the Landcover Changes Based on GIS and RS Technologies: A Case Study of the Sanjiangyuan National Nature Reserve in the Hinterland Tibet Plateau, China
}

\author{
Renjie Zhao ${ }^{1}$, Qingsong $\mathrm{Du}^{2}$ \\ ${ }^{1}$ School of Economics and Management, Northwest University, Xi'an, China \\ ${ }^{2}$ University of Chinese Academy of Sciences, Beijing, China \\ Email: renjiezhao51@outlook.com
}

How to cite this paper: Zhao, R. J., \& Du, Q. S. (2022). Study on the Landcover Changes Based on GIS and RS Technologies: A Case Study of the Sanjiangyuan National Nature Reserve in the Hinterland Tibet Plateau, China. Journal of Geoscience and Environment Protection, 10, 140-150. https://doi.org/10.4236/gep.2022.101010

Received: December 26, 2021

Accepted: January 18, 2022

Published: January 21, 2022

\begin{abstract}
With global warming and increased human activity, more and more ground surface areas have been affected, which leads to the creation of many problems. To understand the ecological environment changes in a typical alpine region, information on landcovers changes in the study area from 2000 to 2020 was obtained by combining remote sensing, geographic information system, and traditional statistical analysis for the Sanjiangyuan National Nature Reserve on the Qinghai-Tibet Plateau, China. The results show that the changes of surface cover in Sanjiangyuan National Nature Reserve are relatively concentrated, mainly distributed in the sections of south, northwest, central, and northeast, with the area of the changed regions and the unchanged regions being $31,127.45 \mathrm{~km}^{2}$ and $271,941.37 \mathrm{~km}^{2}$, respectively. The transformation between the various types of ground landcover is mainly characterized by a shift from other types to grassland and from grassland to bare land. And the regions of change are mostly concentrated between $3500-4600$ $\mathrm{m}$ in elevation.
\end{abstract}

\section{Keywords}

Sanjiangyuan National Nature Reserve (SNNR), Alpine Region,

Qinghai-Tibet Plateau (QTP), Landcover Change, GIS and RS

\section{Introduction}

The Qinghai-Tibet Plateau (QTP) is known as the "Third Pole" of the planet (Zhao et al., 2021; Cheng et al., 2019) because of its unique high-altitude and 
cold geographical characteristics, creating a distinctive climate and a harsh ecological environment in the region. QTP is also known as the "Asian Water Tower" (Yao et al., 2019), as it is the birthplace of most Asian rivers. In recent years, as climate warming and human activity have intensified, even more soon the fragile QTP, more and more scholars and researchers have begun to study its changes all over the world. The deterioration of the ecological environment on QTP will directly or indirectly affect habitat changes in the surrounding areas and even in other regions of the globe, and therefore requires more attention and research.

The Sanjiangyuan National Nature Reserve (SNNR), the largest nature reserve in China, is located in the hinterland of QTP, named from the birthplace of the Yangtze, Yellow, and Lancang Rivers, and it is an important ecological barrier and water-conserving area for China and Asia (Wu et al., 2021). The region of SNNR is home to many endemic Tibetan creatures and richly developed with permafrost, subsurface ice, and other periglacial geomorphologies (Zeng, 2019). Most of the current research on SNNR is focused on natural scientific research and less on the economic and human aspects.

This paper combines remote sensing (RS), geographic information system (GIS), and other technologies (Du et al., 2020) to obtain data on the ecological environment and human and other elements of SNNR, and studies the ecological environment changes in the study area through spatial analysis and statistical analysis methods. Information on land cover changes in the study area from 2000 to 2020 was analyzed using a 2-phase land cover dataset to understand the ecological and environmental change characteristics of SNNR.

\section{Outline of Study Area}

The geographical location of SNNR is $31.45^{\circ} \mathrm{N}-36.04^{\circ} \mathrm{N}, 89.68^{\circ} \mathrm{E}-102.30^{\circ} \mathrm{E}$ (Figure 1), with an area of $303,093.40 \mathrm{~km}^{2}$ and an altitude of $2584-6572 \mathrm{~m}$, with an average elevation of $4540 \mathrm{~m}$ (Figure 1(b)), and it is a typical high-cold and high-altitude area.

The area is dominated by alpine meadows with sparse ground cover and a sparsely populated, grazing population so that changes in grassland are closely related to the standard of living of the local people in SNNR. As the main vegetation type of SNNR, alpine meadows play an extremely important role in the national and global ecological balance (Zhang et al., 2021). The climate of SNNR is typical of the continental climate of the plateau, with annual precipitation of $262.2-772.8 \mathrm{~mm}$ and an average annual temperature of $-5.4^{\circ} \mathrm{C}-4.2^{\circ} \mathrm{C}$. Temperature and precipitation show differences in distribution from the east to the west (Man \& Xu, 2021).

\section{Dataset and Methodology}

For the sake of the research paper in hand, an analysis framework of four main steps (Figure 2) was suggested as follows: 


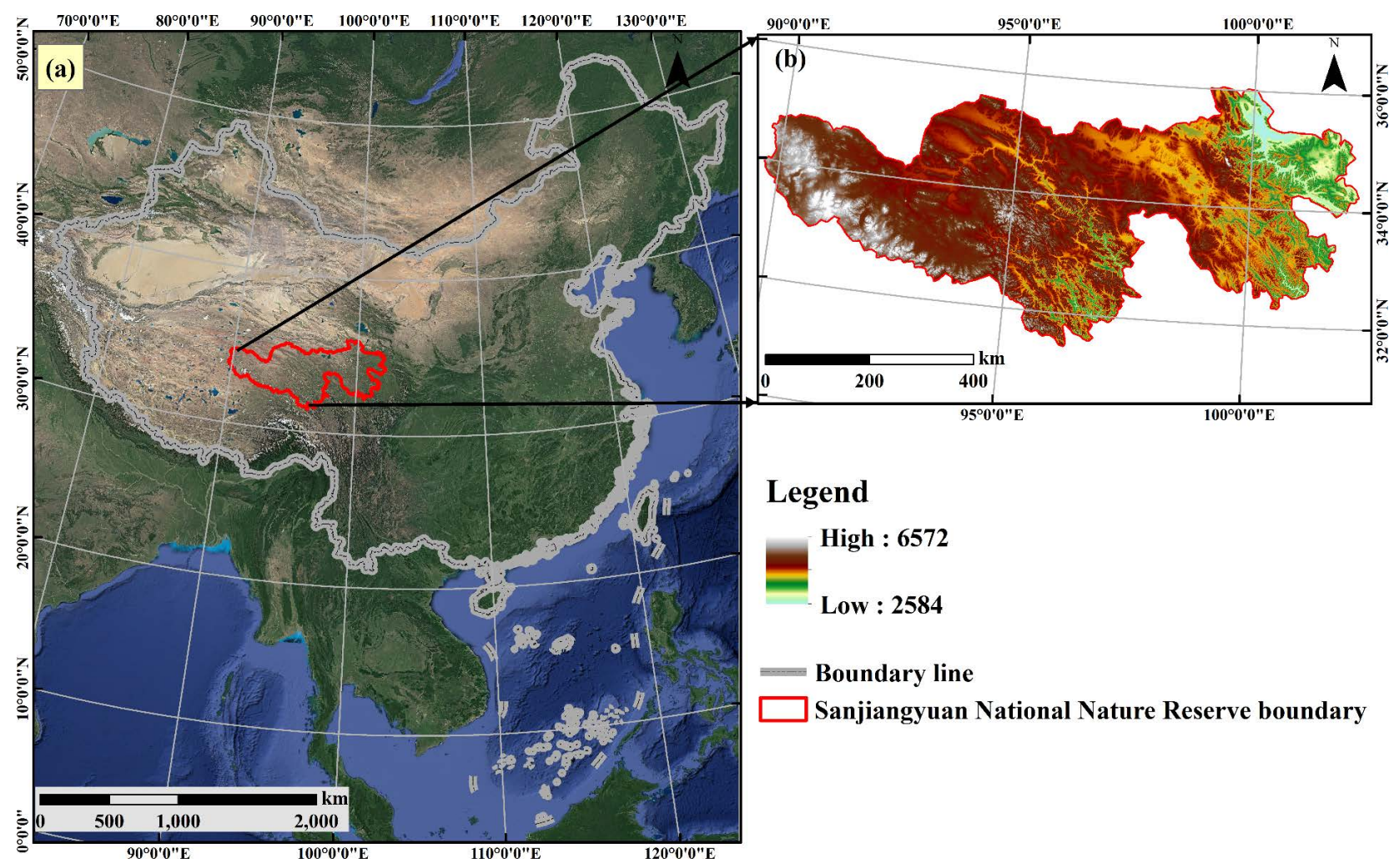

Figure 1. The geographical location of the study area ((a) shows the location of the study area in China; (b) is the DEM (SRTM) of the study area).

\section{Step I: Data preprocessing.}

For better calculations and more efficient analysis, a valid study area boundary is required, which will be used for the determination of the study area and other data reductions. The study area boundary data selected for this paper was obtained from the dataset platform (http://geodata.pku.edu.cn) and extracted through attribute data. To ensure the accuracy of the area, the data used are set to an equal-area projection coordinate system (Krasovsky_1940_Albers).

The pre-processing of the data consists mainly of stitching, coordinate conversion, and cropping of the downloaded DEM data (http://www.gscloud.cn) and surface landcover dataset (http://www.globallandcover.com), with a spatial resolution of $30 \mathrm{~m}$ (GLC 30). The cropping process uses the obtained study area boundary data as the baseline reference. The data used consisted of 2 phases of ground cover data and 8 sections of DEM data.

\section{Step II: Data processing.}

By pre-processing the dataset in the previous step, a 2-phase surface cover raster dataset has been obtained that exactly matches the extent of SNNR. Compared to vector data, raster data is fast to calculate and takes up fewer computer resources to load (Jenson \& Domingue, 1988). Therefore, the raster calculator (Equation (1)) allows the area calculation and change detection of the 2 phases of ground cover data.

$$
S=R \times N
$$




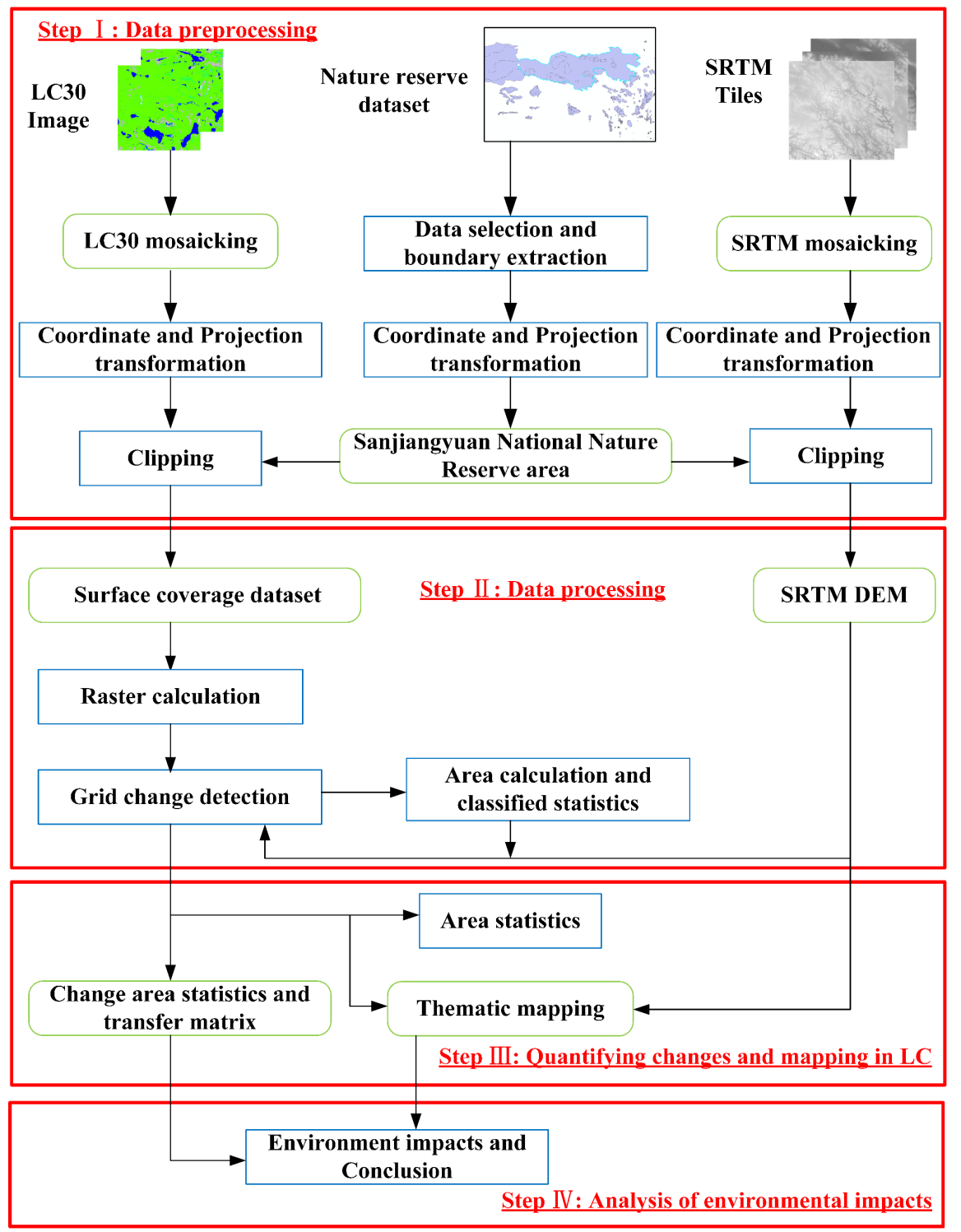

Figure 2. Methodology for the analysis of ground surface cover changes impacts for SNNR through RS and GIS techniques.

where $S$ is the area of the objective; $R$ is the resolution of the land cover dataset, and $N$ is the counting number of the raster.

By counting the number of raster grids, we can quickly calculate the area corresponding to each type of feature and the total area of the study area. At the same time, to obtain information on the land change, we can reduce the value of the raster of surface cover data in 2020 by a factor of 10 and then make a difference with the land cover in 2000, so that we can obtain information on the change between features, with the value corresponding to displacement for each type of change. By counting the number of raster grids for each type of change, and then using Equation (1), we can quickly calculate the area corresponding to it.

Step III: Quantifying changes and mapping in landcover (LC). 
The statistical information from Part II is aggregated to produce a land use transformation transfer matrix, which allows good visualization of the changes between land types. Also, by aggregating the thematic maps of land-use change, the spatial distribution characteristics of the changes can be visualized.

The RGB color used in thematic map mapping is consistent with the original dataset. Seeing Table 1 for the R/G/B color values are corresponding to various features. The whole GLC 30 dataset contains 10 categories in total, and the corresponding attribute code is from 10 to 100 , but the tundra type does not exist in this study area.

\section{Step IV: Analysis of environmental impacts.}

The quantified information has indicated the land changes in the region clearly and by combining the DEM data with the relevant literature, the causes of the changes can be briefly analyzed. In addition, the impact of what such a change would do to the environment needs to be briefly discussed.

\section{Results}

\subsection{Overall Land Cover Changes from 2000 to 2020}

The land cover pattern of SNNR in 2000 and 2020 is shown in Figure 3, and its statistics on land cover change by type are shown in Table 2 .

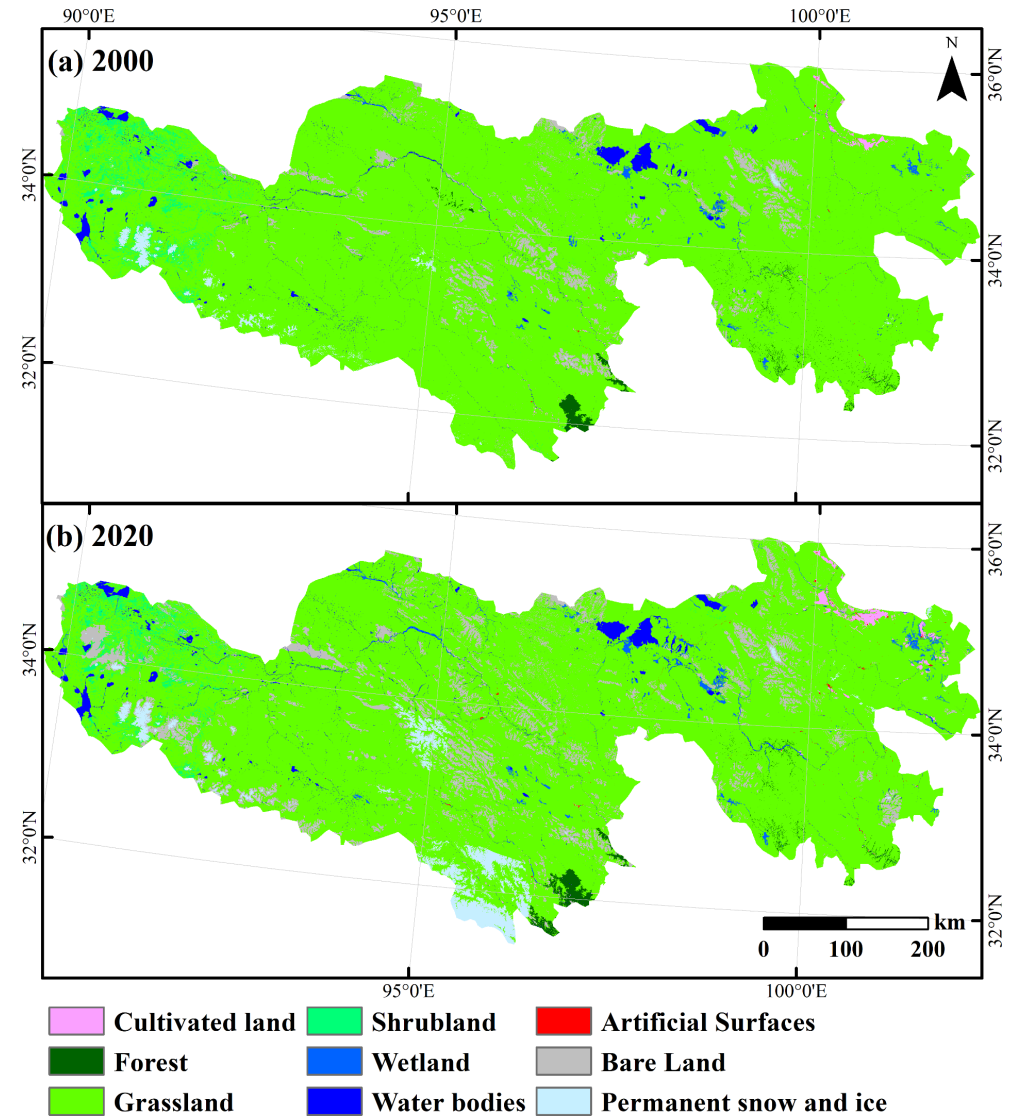

Figure 3. Land cover maps of SNNR ((a) and (b) correspond to the surface cover in 2000 and 2020, respectively). 
Table 1. R/G/B values of the color used in the thematic map of the landcover dataset.

\begin{tabular}{ccccc}
\hline \multirow{2}{*}{ Code } & \multicolumn{3}{c}{ RGB color value } & Landcover Class \\
\cline { 2 - 4 } & R & G & B & Cultivated land \\
10 & 249 & 160 & 255 & Forest \\
20 & 0 & 99 & 0 & Grassland \\
30 & 99 & 255 & 0 & Shrubland \\
40 & 0 & 255 & 119 & Wetland \\
50 & 0 & 99 & 255 & Water bodies \\
60 & 0 & 0 & 255 & Tundra \\
70 & 99 & 99 & 51 & Artificial Surfaces \\
80 & 255 & 0 & 0 & Bare Land \\
90 & 191 & 191 & 191 & Permanent snow and ice \\
100 & 198 & 239 & 255 & \\
\hline
\end{tabular}

Table 2. Statistical information of various types of land coverage in SNNR in 2000 and 2020.

\begin{tabular}{ccccc}
\hline \multirow{2}{*}{ Landcover } & \multicolumn{2}{c}{2000} & \multicolumn{2}{c}{2020} \\
\cline { 2 - 5 } & Area $\left(\mathrm{km}^{2}\right)$ & Ratio (\%) & Area $\left(\mathrm{km}^{2}\right)$ & Ratio (\%) \\
\hline Cultivated land & 681.68 & 0.22 & 1663.27 & 0.55 \\
Forest & 1816.64 & 0.60 & 2212.57 & 0.73 \\
Grassland & $275,491.66$ & 90.89 & $255,266.16$ & 84.22 \\
Shrubland & 6020.46 & 1.99 & 4938.20 & 1.63 \\
Wetland & 1601.68 & 0.53 & 2451.21 & 0.81 \\
Water bodies & 4323.50 & 1.43 & 5001.85 & 1.65 \\
Artificial Surfaces & 55.23 & 0.02 & 206.68 & 0.07 \\
Bare Land & $10,768.35$ & 3.55 & $23,530.53$ & 7.76 \\
Permanent snow and ice & 2334.21 & 0.77 & 7822.85 & 2.58 \\
\hline
\end{tabular}

Grassland was the largest surface cover type in SNNR both in 2000 and 2020, accounting for $90.89 \%$ and $84.22 \%$ of the total area, respectively. The next largest area is bare land, with an area of $10,768.35 \mathrm{~km}^{2}$ and $23,530.53 \mathrm{~km}^{2}$ in 2000 and 2020 respectively, and with an increase of $12,762.18 \mathrm{~km}^{2}$ by 2020 , with an average rate of increase of $638.11 \mathrm{~km}^{2}$. In addition, other types of ground landcovers cover a smaller area, accounting for less than $3 \%$ of the total area. The percentage of the total area is less than $3 \%$ and does not exceed $3 \%$ over the 20 years period, but permanent snow and ice has increased more, from $0.77 \%$ in 2000 to $2.58 \%$ in 2020 , with an increase of over $235.06 \%$.

The overall change in the various types of land cover in SNNR over the 20-year period from 2000 to 2020 is shown in Figure 4, with the largest change 


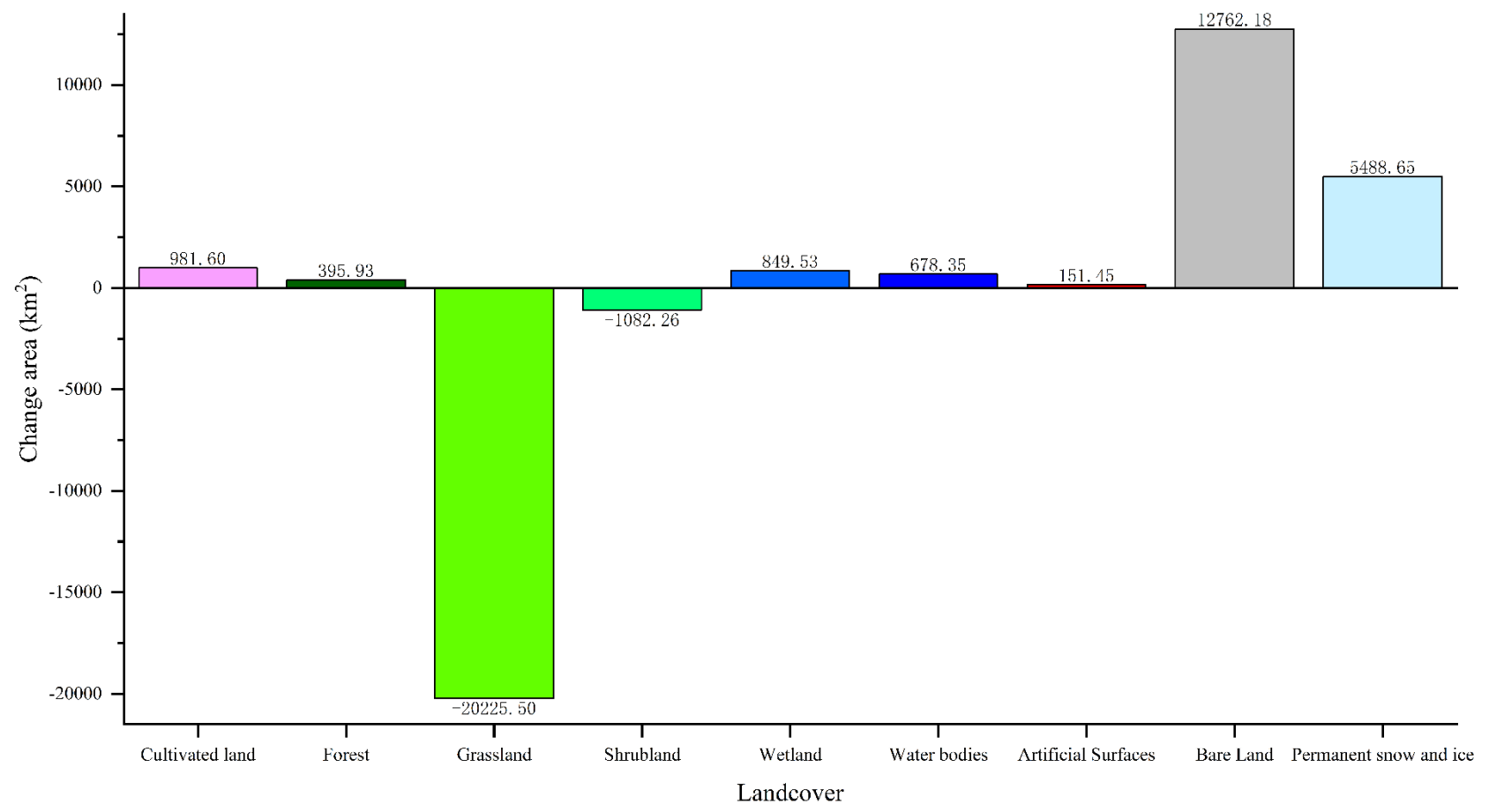

Figure 4. Statistical histogram of various types of land cover changes in SNNR from 2000 to 2020.

in an area being in grassland, followed by bare ground and permanent snow and ice, and the other changes are smaller. In addition, all landcover types show expansion, except for grassland and shrubland, which show contraction. Overall, there has been a degradation of grassland and a shift from grassland to other types of land cover.

\subsection{Spatial and Temporal Characteristics of Land Cover Changes from 2000 to 2020}

The change transfer matrix, which can well represent the changes between each type of land cover and the transformation information between them, shows the change characteristics from the time scale. The transformation of each type of land cover in SNNR during the 20 years from 2000 to 2020 is shown in Table 3.

In terms of the respective types of transformation, cultivated land was mainly transformed into grassland with an area of $1076.92 \mathrm{~km}^{2}$, followed by transformation into the wetland, water bodies, artificial surfaces, and forest with an area of $8.01 \mathrm{~km}^{2}, 5.16 \mathrm{~km}^{2}, 3.28 \mathrm{~km}^{2}$, and $1.08 \mathrm{~km}^{2}$, respectively. The other types are less than $1 \mathrm{~km}^{2}$ and there is no transition to permanent snow and ice.

Forest was also converted mainly to grassland with an area of $701.71 \mathrm{~km}^{2}$, followed by shrubland $\left(18.05 \mathrm{~km}^{2}\right)$, wetland $\left(8.08 \mathrm{~km}^{2}\right)$, water bodies $\left(1.43 \mathrm{~km}^{2}\right)$, cultivated land $\left(1.03 \mathrm{~km}^{2}\right)$, other types less than $1 \mathrm{~km}^{2}$ and no conversion to permanent snow and ice.

There is a shift from grassland to all other types, with the largest being bare land at $1659.97 \mathrm{~km}^{2}$, followed by shrubland at $1179.19 \mathrm{~km}^{2}$. The shift from grassland to other types is also relatively large, with water bodies $\left(535.60 \mathrm{~km}^{2}\right)$, 
Table 3. Land use transfer matrix information of SNNR from 2000 to 2020 (Unit: $\mathrm{km}^{2}$ ).

\begin{tabular}{|c|c|c|c|c|c|c|c|c|c|c|}
\hline & \multirow[b]{2}{*}{ Landcover } & \multicolumn{9}{|c|}{2020} \\
\hline & & $\begin{array}{l}\text { Cultivated } \\
\text { land }\end{array}$ & Forest & Grassland & Shrubland & Wetland & $\begin{array}{l}\text { Water } \\
\text { bodies }\end{array}$ & $\begin{array}{l}\text { Artificial } \\
\text { Surfaces }\end{array}$ & $\begin{array}{l}\text { Bare } \\
\text { Land }\end{array}$ & $\begin{array}{l}\text { Permanent } \\
\text { snow and ice }\end{array}$ \\
\hline \multirow{9}{*}{2000} & Cultivated land & 568.27 & 1.08 & 1076.92 & 0.03 & 8.01 & 5.16 & 3.28 & 0.34 & - \\
\hline & Forest & 1.03 & 1480.02 & 701.71 & 18.05 & 8.08 & 1.43 & 0.003 & 0.87 & - \\
\hline & Grassland & 85.89 & 316.41 & $250,830.61$ & 1179.19 & 436.13 & 535.60 & 10.14 & 1659.97 & 192.55 \\
\hline & Shrubland & 0.03 & 0.11 & 1190.53 & 3712.59 & 0.59 & 16.05 & 0.002 & 11.34 & 6.79 \\
\hline & Wetland & 1.15 & 1.99 & 1169.98 & 34.87 & 1070.41 & 147.73 & 0.47 & 24.59 & - \\
\hline & Water bodies & 4.80 & 6.19 & 1146.43 & 147.21 & 71.56 & 3585.52 & 0.18 & 39.49 & 0.35 \\
\hline & Artificial Surfaces & 19.41 & 0.07 & 143.21 & 0.18 & 0.41 & 1.63 & 40.39 & 1.38 & - \\
\hline & Bare Land & 1.09 & 10.66 & $13,189.02$ & 921.34 & 5.53 & 22.75 & 0.77 & 8948.39 & 429.27 \\
\hline & Permanent snow and ice & - & 0.01 & 6021.74 & 6.30 & 0.85 & 7.21 & - & 80.30 & 1705.16 \\
\hline
\end{tabular}

Note: The symbol "-” indicates that such land-use conversion does not exist, and the conversion type with so small conversion area is reserved to three decimal places.

wetland $\left(413 \mathrm{~km}^{2}\right)$, forest $\left(316.41 \mathrm{~km}^{2}\right)$, cultivated land $\left(85.89 \mathrm{~km}^{2}\right)$, permanent snow and ice $\left(192.55 \mathrm{~km}^{2}\right)$, and artificial surfaces $\left(10.14 \mathrm{~km}^{2}\right)$. The unchanged area is $250,830.61 \mathrm{~km}^{2}$.

Shrubland is transformed into all other types, with an area of $3712.59 \mathrm{~km}^{2}$, mainly into grassland, with an area of $1109.53 \mathrm{~km}^{2}$. The area transformed into water bodies, bare land, and permanent snow and ice is $16.05 \mathrm{~km}^{2}, 11.34 \mathrm{~km}^{2}$, and $6.79 \mathrm{~km}^{2}$ respectively. The area converted to other types of land cover is relatively small, not exceeding $1 \mathrm{~km}^{2}$.

The total area of wetland was $1601.68 \mathrm{~km}^{2}$ in 2000 , increasing by $849.53 \mathrm{~km}^{2}$ by 2020 . The main transformations are grassland $\left(1169.98 \mathrm{~km}^{2}\right)$, water bodies $\left(147.73 \mathrm{~km}^{2}\right)$, shrubland $\left(34.87 \mathrm{~km}^{2}\right)$, bare land $\left(24.59 \mathrm{~km}^{2}\right)$, forest $\left(1.99 \mathrm{~km}^{2}\right)$, and cultivated land $\left(1.15 \mathrm{~km}^{2}\right)$. The transition from wetland to the artificial surface is only $0.47 \mathrm{~km}^{2}$ and there is no transition to permanent snow and ice.

Water bodies are mainly transformed into grassland with an area of 1146.43 $\mathrm{km}^{2}$. Other transformations are shrubland $\left(147.21 \mathrm{~km}^{2}\right)$, wetland $\left(71.56 \mathrm{~km}^{2}\right)$, bare land $\left(39.49 \mathrm{~km}^{2}\right)$, forest $\left(6.19 \mathrm{~km}^{2}\right)$, cultivated land $\left(4.80 \mathrm{~km}^{2}\right)$, permanent snow and ice $\left(0.35 \mathrm{~km}^{2}\right)$, and artificial surfaces $\left(0.18 \mathrm{~km}^{2}\right)$. And the constant area is $3585.52 \mathrm{~km}^{2}$.

Artificial surfaces themselves are smaller in the area and the dynamic transformations that exist are also smaller in area, mainly transforming into grassland $\left(143.21 \mathrm{~km}^{2}\right)$, artificial surfaces $\left(40.39 \mathrm{~km}^{2}\right)$, cultivated land $\left(19.41 \mathrm{~km}^{2}\right)$, water bodies $\left(1.63 \mathrm{~km}^{2}\right)$, and bare land $\left(1.38 \mathrm{~km}^{2}\right)$. The conversion to forest, shrubland, and wetland is all less than $0.5 \mathrm{~km}^{2}$ and there is no conversion to perennial snow and ice.

The conversion of bare land to other surface cover types mainly includes 
grassland $\left(13,189.02 \mathrm{~km}^{2}\right)$, shrubland $\left(921.34 \mathrm{~km}^{2}\right)$, permanent snow and ice $\left(429.27 \mathrm{~km}^{2}\right)$, water bodies $\left(22.75 \mathrm{~km}^{2}\right)$, forest $\left(10.66 \mathrm{~km}^{2}\right)$, wetland $\left(5.53 \mathrm{~km}^{2}\right)$, cultivated land $\left(1.09 \mathrm{~km}^{2}\right)$ and artificial surfaces $\left(0.77 \mathrm{~km}^{2}\right)$.

The type of permanent snow and ice is mainly transformed into grassland $\left(6021.74 \mathrm{~km}^{2}\right)$, bare land $\left(80.30 \mathrm{~km}^{2}\right)$, shrubland $\left(6.30 \mathrm{~km}^{2}\right)$, water bodies $(7.21$ $\left.\mathrm{km}^{2}\right)$, wetland $\left(0.85 \mathrm{~km}^{2}\right)$, and forest $\left(0.01 \mathrm{~km}^{2}\right)$, with an area of $1705.16 \mathrm{~km}^{2}$ unchanged by itself.

In order to better understand the spatial distribution characteristics of land-use change in the study area, the land use dataset of the two periods can be differenced and then binarized, and the results are shown in Figure 5. The area of change is $31,127.45 \mathrm{~km}^{2}$ and the area of no change is $271,941.37 \mathrm{~km}^{2}$.

Figure 5 shows that the changes in the study area are mainly concentrated in the south, northwest, central, and northeast. The changes in the region are more concentrated and distributed in patches. The changes are mainly concentrated between bare land and grassland, with interconversion between surface cover in each area. Combined with the DEM of the study area (Figure 1(b)), it can be seen that the areas of surface cover change in the study area are mainly concentrated in the area between $3500-4600 \mathrm{~m}$ above sea level, and the areas at lower altitudes $(<3000 \mathrm{~m})$ and very high altitudes $(>5000 \mathrm{~m})$ have little change in surface cover and are relatively stable.

\section{Discussion}

The processing of the 2-phase ground cover raster data allows for quick access to information on land-use change in the area of interest. However, there are some flaws in the processing that need attention.

The accuracy of research results is highly dependent on the credibility of the data used. Because the data used is the basis for the analysis, incorrect data will not lead to scientifically accurate results and conclusions. The overall accuracy of the ground cover data chosen for this paper is high (overall accuracy is $85.72 \%$, and with the Kappa of 0.82) that of a large number of previous applications and uses (Chen et al., 2014; Chen et al., 2016). Therefore, the results of this paper are

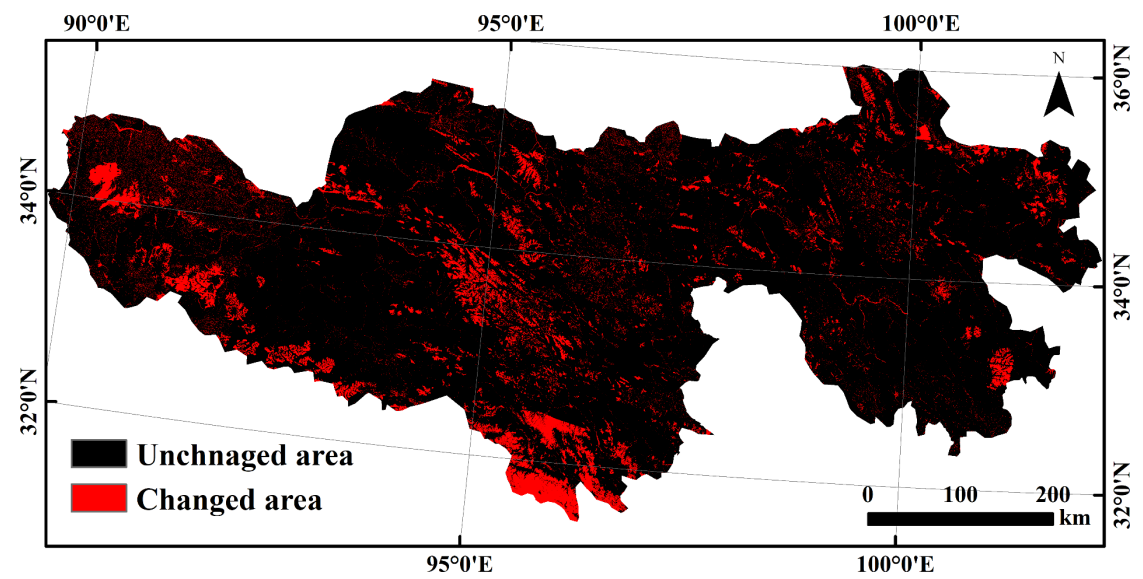

Figure 5. Spatial distribution map of surface land changes in SNNR from 2000 to 2020. 
scientifically sound and accurate. Of course, if more accurate ground cover data were available, it would be inevitable to improve the results of the study.

In the process of mosaicking the ground cover data, we found small areas with black patches and the presence of black borders in the overlapping areas. For the black borders, the approach in this paper is to make a maximum extraction process for the overlapping parts during the mosaic, i.e., where the overlapping parts are, take their maximum value. The rationale for this operation is that black borders have a value of 0 , while the useful feature data values are all positive integers greater than 0 . In addition, the ground cover data values are the same in the overlapping areas, except for the black border. Therefore, the effect of the black border can be perfectly avoided by extracting its maximum value in the overlapping area.

For the small black areas in the non-overlapping areas (caused by missing data or source data processing errors), this paper deals with them by observing that they exist in the grassland distribution area, so these small black areas are directly reassigned to the corresponding values of grassland, i.e., they are directly classified as grassland. Of course, this is only practical for smaller areas of the study area, and for larger areas, cluster analysis and small spot removal can be used.

\section{Conclusion}

The land cover transformation in SNNR during the 20-year period from 2000 to 2020 was mainly between grassland and bare ground, with a greater trend towards grassland in all other types of land cover, and grassland mainly transformed into bare ground. The transformation areas in the study area are mainly concentrated in the south, northwest, central, and northeast of the study area, with the area of changed and unchanged areas being $31,127.45 \mathrm{~km}^{2}$ and $271,941.37 \mathrm{~km}^{2}$ respectively.

The net changes in land transformation area over the 20 -year period were grassland $\left(20,225.50 \mathrm{~km}^{2}\right)$, bare land $\left(12,672.18 \mathrm{~km}^{2}\right)$, permanent snow and ice $\left(5488.65 \mathrm{~km}^{2}\right)$, shrubland $\left(1082.26 \mathrm{~km}^{2}\right)$, cultivated land $\left(981.60 \mathrm{~km}^{2}\right)$, wetland $\left(849.53 \mathrm{~km}^{2}\right)$, water bodies $\left(678.35 \mathrm{~km}^{2}\right)$, forest $\left(359.93 \mathrm{~km}^{2}\right)$ and artificial surfaces $\left(151.45 \mathrm{~km}^{2}\right)$, with a decrease in grassland and shrubland and an increase

in the others. The area of change is mainly concentrated in the area between $3500-4600 \mathrm{~m}$ above sea level, and the change in a surface cover is relatively stable at regions with lower altitudes $(<3000 \mathrm{~m})$ and very high altitudes $(>5000 \mathrm{~m})$.

\section{Conflicts of Interest}

The authors declare that there are no conflicts of interest regarding the publication of this paper.

\section{References}

Chen, J., Ban, Y., \& Li, S. (2014). China: Open Access to Earth Land-Cover Map. Nature, 
514, 434-434. https://doi.org/10.1038/514434c

Chen, J., Chen, J., Liao, A. et al. (2016). Remote Sensing Mapping of Global Land Cover. Science Press.

Cheng, G., Zhao, L., Li, R., Wu, X., Sheng, Y., Hu, G., Zou, D., Jin, H., Li, X., \& Wu, Q. (2019). Characteristic, Changes and Impacts of Permafrost on Qinghai-Tibet Plateau. Chinese Science Bulletin, 64, 2783-2795. https://doi.org/10.1360/TB-2019-0191

Du, Q., Li, G., Peng, W., Chai, M., Zhou, Y., \& Chen, D. (2020). Land Use Changes in High Cold-Altitude Mining Area Based on Remote Sensing Technology. Environmental Science \& Technology, 43, 185-194. https://doi.org/10.19672/j.cnki.1003-6504.2020.12.025

Jenson, S. K., \& Domingue, J. O. (1988). Extracting Topographic Structure from Digital Elevation Data for Geographic Information-System Analysis. Photogrammetric Engineering and Remote Sensing, 54, 1593-1600. https://doi.org/10.1109/36.7721

Man, W., \& Xu, Y. (2021). Using NPP and EVI to Assess the Ecological Status of the Sanjiangyuan Area. Grassland and Turf, 41, 1-8.

Wu, G., Li, X., \& Gao, J. (2021). The Evolution of Hummock-Depression Microtopography in an Alpine Marshy Wetland in Sanjiangyuan as Inferred from Vegetation and Soil Characteristics. Ecology and Evolution, 11, 3901-3916.

https://doi.org/10.1002/ece3.7278

Yao, T., Wu, G., Xu, B., Wang, W., Gao, J., \& An, B. (2019). Asian Water Tower Change and Its Impacts. Bulletin of Chinese Academy of Sciences, 34, 1203-1209.

https://doi.org/10.16418/j.issn.1000-3045.2019.11.003

Zeng, Y. (2019). Response and Adaptation of Ecosystem Recreational Potential in Sanjiangyuan to Climate Change. Doctoral Thesis of Science in Human Geography, Institute of Geographic Sciences and Natural Resources Research, CAS.

Zhang, H., Chen, Z., Zhang, X., Zhang, L., \& Ji, S. (2021). Evaluation of Carbon Sequestration by Vegetation and Its Influencing Factors from 1977 to 2017 in the Three-River Source Region. Acta Scientiarum Naturalium Universitatis Nankaiensis (Natural Science Edition), 54, 87-100.

Zhao, L., Zou, D., Hu, G., Wu, T., \& Cheng, G. (2021). A Synthesis Dataset of Permafrost thermal State for the Qinghai-Xizang (Tibet) Plateau, China. Earth System Science Data, 13, 4207-4218. https://doi.org/10.5194/essd-13-4207-2021 